\title{
China's new mAb institute
}

\section{By Tim Fulmer, Senior Writer}

The launch of the Shanghai Institute for Advanced Immunochemical Studies marks China's first attempt to establish a center of antibody research on par with research centers in the U.S. and Europe. Although details are still sparse, the institute will identify targets and develop antibodies to treat cancer as well as infectious, autoimmune and metabolic diseases.

This month, the Chinese Academy of Sciences held a ceremony in Shanghai marking the launch of the Shanghai Institute for Advanced Immunochemical Studies (SIIS) by the University of Shanghai for Science and Technology (USST) and the Shanghai Advanced Research Institute. American researcher Richard Lerner was appointed head of the governing

"China is serious about getting into the mAb game now, and the purpose of the new institute is to get critical mass in modern immunochemistry by bringing together the right labs that work on antibodies and putting them under the same roof."

\section{-Richard Lerner,}

The Scripps Research Institute advisory board of the new institute.

The board will function much like a scientific advisory board, said Lerner. The other board members have not been disclosed.

Lerner is former president and CEO of The Scripps Research Institute, where he now is professor of immunochemistry, a position he will retain.

"China is serious about getting into the mAb game now, and the purpose of the new institute is to get critical mass in modern immunochemistry by bringing together the right labs that work on antibodies and putting them under the same roof," Lerner told SciBX. "That arrangement should make for solid collaborations and lead to innovative research."

SIIS will be located in its own building, which is being constructed on the USST campus. It will house the labs of researchers drawn from USST and potentially other institutes and universities in China.

SIIS will be run by a CEO and COO, who have been recruited but will be announced at a later time, according to Lerner. He could not disclose whether they are Chinese or have come from outside the country.

The overarching theme of the new institute is next-generation approaches to $\mathrm{mAb}$ therapeutics, said Lerner.

"Some initial areas of interest include orally delivered mAbs, cellpermeable $\mathrm{mAbs}$, agonist $\mathrm{mAbs}$ and $\mathrm{mAbs}$ armed with organic small molecules. We will also look at indications not usually associated with mAb therapies such as metabolic disorders," he said. "There are also plans to generate an antigenic map of human cells, which should allow for the identification of new mAb targets not identified by standard firstgeneration approaches that rely on combinatorial libraries."

Lerner said he and the CEO and COO are discussing what the institute's research focus areas should be and which labs might make the best fit.

USST and the Chinese Academy of Sciences did not respond to requests for an interview.

Lerner is not the first big-name U.S. scientist to take on a major role at a Chinese research institute. Over the past decade, life science researchers from multiple U.S. universities have been recruited to found and/or direct and advise institutes.

In 2002, Tian Xu, Min Han and Yuan Zhuang founded and became co-directors of the Institute of Developmental Biology and Molecular Medicine (IDM) at Fudan University. The IDM includes 10 primary faculty members and over 150 research personnel.

All three co-directors retain their U.S. academic positions. $\mathrm{Xu}$ is professor at the Yale School of Medicine and vice chair of the Department of Genetics. Han is professor of molecular, cellular and developmental biology at the University of Colorado at Boulder. Zhuang is professor of immunology and molecular genetics and microbiology at Duke University.

In 2003, Xiaodong Wang resigned his appointment as professor in biomedical science at The University of Texas Southwestern Medical Center to run Beijing's National Institute of Biological Sciences (NIBS), then a new research center in Beijing modeled after the Howard Hughes Medical Institute.

NIBS was formed as part of a government initiative to promote the development of science and technology in China. ${ }^{2}$

Fulmer, T. SciBX 5(42); doi:10.1038/scibx.2012.1101

Published online Oct. 25, 2012

REFERENCES

1. Koenig, R. HHMI Bulletin 23(1), 25-29 (2010)

2. Schaeffer, S. BioCentury 18(50), A1-A4; Nov. 15, 2010

COMPANIES AND INSTITUTIONS MENTIONED

Chinese Academy of Sciences, Beijing, China

Duke University, Durham, N.C.

Fudan University, Shanghai, China

Howard Hughes Medical Institute, Chevy Chase, Md. Institute of Developmental Biology and Molecular Medicine,

Shanghai, China

National Institute of Biological Sciences, Beijing, China

The Scripps Research Institute, La Jolla, Calif.

Shanghai Advanced Research Institute, Shanghai, China Shanghai Institute for Advanced Immunochemical Studies, Shanghai, China

University of Colorado at Boulder, Boulder, Colo.

University of Shanghai for Science and Technology, Shanghai, China

The University of Texas Southwestern Medical Center, Dallas, Texas

Yale School of Medicine, New Haven, Conn. 